\title{
Border crossings
}

Biodiversity hotspots don't often fit neatly within political borders, and most span at least two or three countries. Establishing transboundary conservation areas is a complex and difficult process, but one that can bring socioeconomic benefits to a region as well as conserving its biodiversity.

Transboundary Conservation: A New Vision for Protected Areas (Conservation International/Agrupacion Sierra Madre, $\$ 50$ ) by Russell A. Mittermeier et al. introduces the history of this type of conservation initiative. It surveys examples from every continent, including the first, Waterton-Glacier International Peace Park between Canada and the United States, established in 1932, and the largest, the Great Limpopo Transfrontier Park. Antarctica, the last global commons (pictured here), is also included in this book, which uses the power of photography to help propel the conservation agenda.

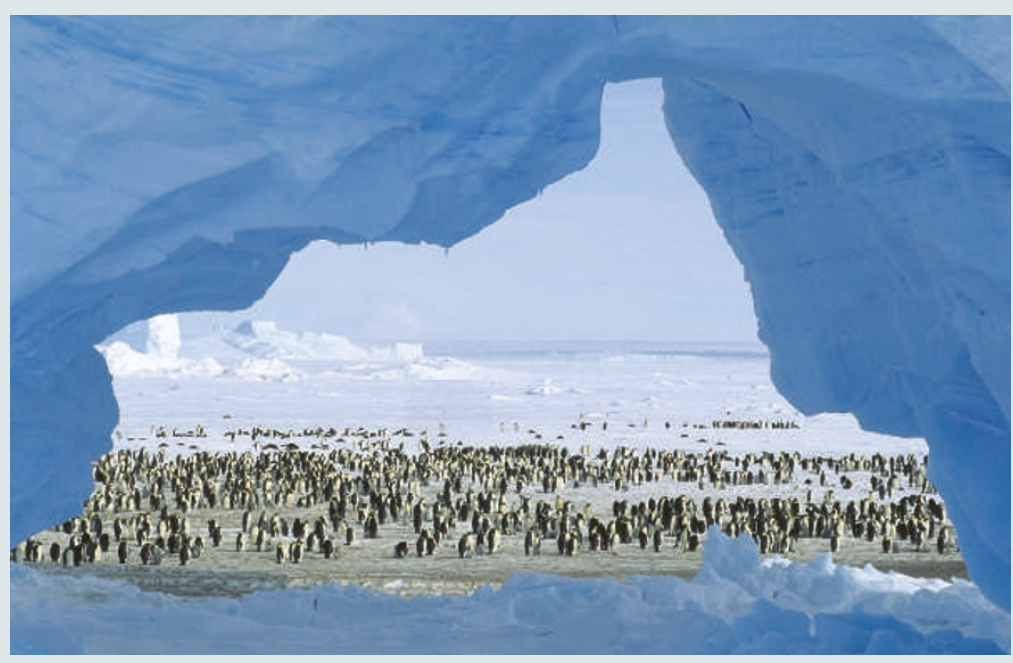

\section{The moral element}

\section{Against Bioethics \\ by Jonathan Baron \\ MIT Press: 2006.248 pp. $\$ 29, £ 18.95$}

\section{Prashanth Ak}

How should public-policy issues that involve an ethical component be decided? Should we rely on moral intuition? Can we apply some standard rules? Advances in medical and biological research mean that we continue to face these age-old questions in new situations. How should we legislate genetic manipulations or triage healthcare resources? In Against Bioethics, Jonathan Baron argues that current bioethical practices are predominantly based on "tradition and intuitive judgments", and he proposes instead a systematic approach to bioethical analysis and decision-making.

Most readers of Nature, trained as we are in the scientific process, will have no difficulty in agreeing with the need for a clear, systematic analysis and evaluation of possible outcomes, such as that advocated by Against Bioethics. But how do we proceed? What framework do we use? In an admirably concise, lucidly written exposition, Baron proposes that we use decision analysis, with utilitarianism as the moral framework. He addresses specific problems such as drug research, death and end-of-life issues (including advance directives, euthanasia and organ donation), informed consent and the practices of institutional review boards. The book delivers a praiseworthy analysis of problems in these areas with a rigorous application of clear, consistent methods.

However, there is a major impediment to the wide acceptance of the methods he proposes: the utilitarian framework is controversial, and various objections have been raised against such frameworks before.

Moral theories fall into roughly two categories. The first kind bases the rightness or wrongness of an act on the consequences (for example, cheating is wrong because of the bad consequences it produces). The second category claims that rightness or wrongness is inherent in the nature of the act itself (cheating is morally wrong, even when it produces good consequences). An example of the first category, utilitarianism, simply stated, posits that a moral act is one that maximizes utility, or 'good' consequences. It has permeated Western intellectual life as a philosophy over the past two centuries, especially in law, politics and economics. But its influence has been counterpointed by deontological ideas, such as morality independent of consequence, and inalienable fundamental rights. Indeed, much of current thinking on morality and ethics in the Western world has been an unsettled balance between such deontological ideas and utilitarianism. This uneasy truce, in various forms, spans the history of Western civilization - ever since the young Socrates, using utilitarian ideas, vigorously rejected the Sophists' claims of common morality. The debate continues.

Against Bioethics is not intended as a defence of utilitarianism per se, and is unlikely to sway its opponents. Acting to maximize 'good' consequences seems sensible, but whether the whole of normative ethics can be analysed in these terms is far from settled. If one is part of a minority that frequently has to make sacrifices for the good of the majority, it can get tiresome in the long run. 'Good', in any case, is difficult to define, let alone measure. Partly because of this difficulty, various modified and complicated formulations of utilitarianism exist today, with different definitions of 'good': as pleasure (by Jeremy Bentham); happiness (John Stuart Mill); ideals, such as freedom, justice and beauty (George Moore); preferences, or satisfaction by things of intrinsic value
(Richard Hare). Regardless of whichever definition of 'good' is acceptable (and for the most part, Against Bioethics seems to favour 'preferences'), measuring 'good' is difficult, especially over time and across a pluralistic society. It is sobering to note that Henry Sidgwick's 1874 volume The Methods of Ethics, arguably the most detailed and subtle exposition of utilitarianism available, concludes: "it would seem necessary to abandon the idea of rationalizing [morality] completely."

A significant feature of Against Bioethics is the application of decision analysis to bioethical problems. An offshoot of statistical decision theory, decision analysis enables an optimal choice from a set of alternatives in the face of uncertainty (allowing the use of probabilistic criteria where possible). It is similar to utilitarianism in that decisions are made on the criterion of maximization (of utility, for example). Both claim that, in principle, all relevant considerations can be reduced to a utility function, which allows for comparisons. However, decision analysis is 'morally blind' as it does not cater to any particular moral framework - it can easily incorporate utilitarian or non-utilitarian concerns. Decision analysis as a procedure for systematically analysing bioethical problems would perhaps be more acceptable if it were not used within a utilitarian framework as Against Bioethics proposes.

There is a need to address bioethical issues, and in Against Bioethics Baron at least gives us pause for thought. Its starting point, that much is lacking in current bioethical practices, is certainly worth considering. All too often in bioethical decisions, competing principles are intuitively balanced and applied ad hoc. Development of a thorough, coherent theory to guide and systematize practices and policies can only help. Initiatives such as this book are especially welcome, and will hopefully serve to instigate debate and discussion.

Prashanth Ak is at the Genome Center, University of California, Davis, California 95616-8816, USA. 